\title{
Interculturalidade e ensino de artes visuais do Colégio Pedro II
}

\author{
Wilson Cardoso Junior* \\ Universidade Federal do Rio de Janeiro \\ Vera Maria Ferrão Candau** \\ Pontifícia Universidade Católica do Rio de Janeiro
}

Resumo Esse trabalho apresenta um estudo de caso sobre o ensino de artes visuais em busca de compreender sobre o processo de construção de uma perspectiva de educação intercultural nessa disciplina escolar no Colégio Pedro II. Por meio da análise de documentos curriculares e entrevistas realizadas com professores/as, em interlocução com a educação intercultural crítica e descolonizadora referenciada no pensamento pós-abissal, verificou-se que a construção da perspectiva intercultural no primeiro segmento do Ensino Fundamental, produzida em diálogo com a pedagogia da cultura visual e o ensino intercultural de artes visuais, tem ocorrido em meio a tensões e disputas com os/as defensores/as da concepção de arte-educação tradicional centrada na obra de arte, estabelecida predominantemente no segundo segmento do Ensino Fundamental. As reflexões finais apontam para o desafio da construção de um projeto de formação intercultural de professores/as de artes visuais em fricção com a sistematização eurocêntrica da história da arte que preside os currículos dessa disciplina na escola básica e nos cursos de formação inicial de professores/as.

PALAVRAS-CHAVE: Ensino de artes visuais; Educação intercultural crítica; Colégio Pedro II. 


\section{Interculturality and visual arts teaching at Colégio Pedro II}

Abstract This paper presents a case study on the teaching of the visual arts in an attempt to understand the process of constructing a perspective of intercultural education in this school discipline in Colégio Pedro II. Through the analysis of curricular documents and interviews with teachers, in interlocution with the critical intercultural education and decolonization referenced in post-abyssal thought, it was verified that the construction of the intercultural perspective in the first segment of Elementary Education, produced in dialogue with the pedagogy of visual culture and the intercultural teaching of the visual arts, has occurred amid tensions and disputes with the defenders of the conception of traditional art education centered in the work of art, established predominantly in the second segment of Elementary Education. The final reflections point to the challenge of constructing a project of intercultural training of teachers of visual arts in friction with the Eurocentric systematization of art history that presides over the curricula of this discipline in basic school and in the courses of initial formation of teachers / at.

KEYWORDS: Teaching of visual arts; Critical intercultural education; Colégio Pedro II.

A disciplina Artes Visuais faz parte do currículo do Colégio Pedro II (CP II) há mais de quarenta anos, desde a obrigatoriedade exigida pela LDBEN N 9o 5.692, de 1971. Atualmente, ela é lecionada em treze anos ininterruptos da Educação Básica com um percurso que vai da Educação Infantil (três anos letivos) até o $1^{\circ}$ ano do Ensino Médio, passando pelos dois segmentos do Ensino Fundamental (nove anos).

Nessa tradicional instituição de ensino brasileiro, o conjunto de professores/as de Artes Visuais tem acolhido a temática do multiculturalismo na educação e, desde o início do século XXI, ela está presente no debate existente no Departamento de Artes Visuais sobre a relação entre a disciplinarização da arte e a tradição curricular monocultural baseada nos cânones artísticos ocidentais. As discussões colocam em questão o próprio conceito de arte, a configuração de seu campo de ensino e a suposta neutralidade da hegemonia curricular dos conhecimentos com ancoragem histórica na Europa ocidental

Esse debate, que tem impactado os programas curriculares, se caracteriza pela disputa de sentidos sobre as finalidades dessa disciplina escolar envolvendo duas concepções distintas que se apresentam em antagonismo, a saber. No Ensino Fundamental / Anos Finais predomina a arte-educação tradicional, centrada na obra de arte como objeto de estudo absoluto. No Ensino Fundamental / Anos Iniciais vigora a tendência para a educação para a cultura visual, considerando-se um conteúdo curricular ampliado que, por um lado, vai além da arte e toma como artefatos educativos outros fenômenos visuais; e por outro lado, vai além da matriz artística europeia e incorpora as culturas artísticas africanas, indígenas e populares. 
Por meio desse estudo de caso ${ }^{1}$ buscamos compreender um processo de interculturalização do ensino de artes visuais na educação escolar, como uma pista ou sinal daquilo que ainda é tendência ou possibilidade existente no presente como portador de futuro. Para tanto, foram utilizados os instrumentos de pesquisa de análise documental e entrevistas com docentes a partir das seguintes questões: que arte tem sido legitimada na escola? Como as artes indígenas, europeias, africanas e afro-brasileiras estão inscritas no currículo? Como lidar com a unilinearidade eurocêntrica que preside a sistematização da história da arte encontrada tanto nos currículos da escola básica quanto naqueles que orientam a formação inicial de professores/as de artes visuais, de maneira a contemplar a perspectiva da educação intercultural?

Esse trabalho possui a seguinte estruturação. De início, a fim de estabelecer a perspectiva de educação intercultural crítica, é feita a discussão sobre os conceitos de multiculturalismo e interculturalidade no campo de ensino de artes visuais. A seguir, observa-se criticamente a relação entre currículo e epistemologia do conhecimento escolar de artes visuais no ensino fundamental do Colégio Pedro II (CP II). Nas considerações finais são apresentadas reflexões sobre alguns dos principais desafios da educação intercultural do ensino de Artes Visuais.

\section{Educação intercultural e ensino de artes visuais}

A educação intercultural crítica é uma perspectiva em construção no campo educacional brasileiro que vem sendo desenvolvida por Vera Candau a partir da seguinte definição:

A educação intercultural parte da afirmação da diferença como riqueza. Promove processos sistemáticos de diálogo entre diversos sujeitos - individuais e coletivos -, saberes e práticas na perspectiva da afirmação da justiça - social, econômica, cognitiva e cultural -, assim como da construção de relações igualitárias entre grupos socioculturais e da democratização da sociedade, através de políticas que articulam direitos da igualdade e da diferença. (CANDAU, 2016, p. 10-11).

São propostos dois princípios fundamentais: o questionamento / desconstrução do caráter monocultural das culturas escolares e a promoção da educação intercultural. Busca-se operar com eles de maneira simultânea e entrelaçada, sobre quatro dimensões educativas: os sujeitos/atores (individuais e coletivos), os conhecimentos/ saberes, as práticas pedagógicas e as políticas públicas.

Do ponto de vista dos conhecimentos / saberes - a dimensão de maior interesse desse trabalho devido ao recorte no currículo do CP II -, propõe-se dar visibilidade ao atravessamento dos conhecimentos escolares por relações de poder a fim de questionar o caráter monocultural e etnocêntrico das culturas escolares, desestabilizar hierarquias epistemológicas e desconstruir a folclorização das culturas não ocidentais, especialmente as indígenas e africanas.

Tal questionamento se faz pari passu com a identificação, valorização e interação entre diversos saberes presente no cotidiano escolar, a análise da ancoragem his- 
tórica e social dos diferentes conhecimentos curricularizados e a reflexão crítica sobre os próprios referentes culturais. Compreende-se ainda a valorização da hibridização cultural proveniente da convivência horizontal de saberes, de maneira a romper com visões essencialistas das identidades culturais.

Busca-se promover a discussão sobre a relação entre universalismo e relativismo do ponto de vista epistemológico, compreendendo-se que a seleção de conhecimentos é uma questão que deve ser mantida em estado de tensão, sem ceder ao relativismo absoluto (propício à guetificação e à negação da construção coletiva entre os/as diferentes) e sem pretender definições pré-estabelecidas e transcendentais. De acordo com essa visão, compreende-se o currículo como construção dinâmica baseada em negociações culturais permanentes tendo por horizonte a "construção de sociedades democráticas e inclusivas, que articulem políticas de igualdade com políticas de identidade." (CANDAU, 2009, p.58).

Importa destacar que, segundo Candau (Ibidem, p.58), essa perspectiva denominada de multiculturalismo aberto e interativo, convive com outras duas concepções baseadas em diferentes proposições educacionais que relacionam o multiculturalismo e os conhecimentos escolares a partir da tensão entre universalismo e relativismo cultural. São elas: o multiculturalismo assimilacionista e o multiculturalismo diferencialista.

A perspectiva assimilacionista propõe uma política de universalização da escolarização sem que se coloque em questão o caráter monocultural dos conteúdos privilegiados no currículo, camuflando a sua ancoragem histórica a fim de que sejam tomados como universais, neutros e inquestionáveis. O multiculturalismo diferencialista tende a uma concepção estática e essencialista da formação das identidades culturais devido a negação da universalidade de qualquer saber e valor afirmado na escola. Essa visão, não raro, favorece à guetificação e à negação da construção coletiva entre os/ as diferentes.

A educação intercultural crítica, decorrente do multiculturalismo aberto e interativo, vem sendo fertilizada pela obra do sociólogo português Boaventura de Sousa Santos. De sua vasta obra importa-nos aqui o pensamento pós-abissal, a concepção de Epistemologias do Sul e o conceito de ecologia de saberes. A eles estão associados os dois procedimentos metodológicos que operam articuladamente: a Sociologia das Ausências e a Sociologia das Emergências.

O autor compreende que as Epistemologias do Norte foram universalizadas no período colonial - quando grande parte da população mundial esteve sob o domínio de povos ocidentais - pelas três principais fontes de opressão que atuam conjuntamente no mundo desde o início da modernidade: capitalismo, colonialismo e patriarcado. $\mathrm{O}$ projeto de colonização cultural empreendido por povos europeus consistiu em universalizar (transcendentalizar) um localismo (conhecimentos com ancoragem histórica e geográfica específica) pela divisão planetária determinada (unilateralmente) por uma linha abissal que criou dois universos diferentes: o Norte, portador de visibilidade e caracterizado como "território metropolitano", e o Sul, portador de 
"invisibilidade" e denominado como "território colonial" (SANTOS, 2010). Por essa divisão o Sul, onde se localizam os "outros" sujeitos e culturas fora do padrão hegemônico, torna-se inexistente no sentido da existência sem relevância, entendida como "uma alternativa não-crível, como uma alternativa descartável, invisível à realidade hegemônica do mundo” (SANTOS, 2007, p. 28-29).

Em contraposição a essa estratégia colonial histórica, as Epistemologias do Sul significam o reconhecimento e a legitimação de um conjunto de conhecimentos produzidos e a produzir pelos sujeitos que sofreram e estão a sofrer sistematicamente opressão, injustiça, dominação, exclusão e invisibilidade, contrariando a geopolítica do conhecimento imposta pelo capitalismo internacional.

A ideia de ecologia dos saberes baseia-se na promoção da "conversa do mundo" que é mais ampla, rica e horizontal do que a compreensão ocidental do mundo (SANTOS, 2007, p. 20), propondo-se a trazer para esse diálogo formas de conhecimento que foram ocultadas pelo nortecentrismo. A ecologia de saberes contribui para a reinvenção da emancipação social baseada no pressuposto de que "não há justiça social global sem justiça cognitiva global, ou seja, sem justiça entre os conhecimentos" (Ibidem, p. 40). Sua proposição não busca a "descredibilização" das ciências - conhecimento hegemônico na educação e nas sociedades modernas - e nem se alinha com posições fundamentalistas "anticiência", mas investe na desconstrução de sua hegemonia. Por isso propõe o uso contra-hegemônico dos conhecimentos científicos a fim de integrá-los "como parte de uma ecologia mais ampla de saberes, em que o saber científico possa dialogar com o saber laico, com o saber popular, com o saber dos indígenas, com o saber das populações urbanas marginais, com o saber camponês." (Ibidem, p. 32-33).

Santos propõe a conjugação da Sociologia das Ausências e da Sociologia das Emergências para cumprir com esse intuito. A primeira se presta a dilatar o presente para nele revelar a diversificação e a multiplicação de outras experiências humanas disponíveis, possibilitando a proliferação de outras formas de conhecimento e saberes para a construção de "práticas de agregação da diversidade pela promoção de interações sustentáveis entre entidades parciais e heterogêneas” (Ibidem, p. 105).

A Sociologia das Emergências, formulada para confrontar a razão proléptica (assentada na ideia linear de progresso), propõe obter um "futuro concreto, de utopias realistas, suficientemente utópicas para desafiar a realidade que existe, mas realistas para não serem descartadas facilmente"(Ibidem, p.37). Trata-se de uma forma de agir sobre o Ainda-Não, sobre aquilo que ainda não é, mas se mostra como potência e potencialidade para vir a ser. Essa forma de agir significa a ampliação simbólica de, por exemplo, uma pequena ação coletiva, de um pequeno movimento social, o que requer atenção às pistas e aos sinais daquilo que ainda é tendência ou possibilidade existente no presente como portador de futuro.

De acordo com Sacavino (2016), pensar a educação intercultural crítica num marco de descolonização, em contraposição à globalização hegemônica, neoliberal e colonizadora, significa relacioná-la à construção de um projeto social, cultural, educativo, político, ético e epistemológico voltado para a existência digna de todos e 
todas. Projeto este para o qual é fundamental a construção de novas subjetividades, descolonizadas e interculturais, por meio de processos educativos voltados para a descolonização do ser, da mente, do imaginário e da memória.

Para tanto, faz-se imprescindível não reduzir o entendimento de interculturalidade à inclusão de novos temas nos currículos ou nas metodologias pedagógicas.

\begin{abstract}
(...) a interculturalidade não só é compreendida como um conceito ou um termo novo para se referir ao contato entre ocidente e outras civilizações, mas como uma configuração conceitual que propõe um giro epistêmico capaz de produzir novos conhecimentos e outras compreensões simbólicas do mundo. A interculturalidade, entendida desde essa perspectiva, representa a construção de um novo espaço epistemológico que inclui os conhecimentos subalternizados e os ocidentais, em uma relação tensa, crítica e mais igualitária. (SACAVINO, 2016, p. 193)
\end{abstract}

No campo de ensino de artes visuais, as questões culturais ganharam centralidade no Brasil a partir do início do século XXI com um conjunto de proposições voltadas para o entrelaçamento entre arte e cultura; a compreensão dos códigos culturais como códigos de poder; a defesa da apropriação crítica dos códigos dominantes presentes nos artefatos visuais, legitimados ou não como arte; a preocupação com a herança artística e estética dos/as alunos/as; o compromisso com a diversidade cultural.

Essas características fazem parte da perspectiva contemporânea de ensino de artes visuais que comporta duas expansões em relação ao conceito de belas-artes que define a arte como disciplina histórica a ser ensinada na escola, a saber. Por um lado, a vertente da educação intercultural em artes visuais, de cunho disciplinar, questiona a cultura artística monocultural de matriz europeia e promove o reconhecimento, a contemporaneidade, a incorporação e a interação não hierarquizada das culturas artísticas de matrizes africanas, indígenas e populares. Por outro lado, a educação para a cultura visual, de caráter transdisciplinar e/ou pós-disciplinar, que compreende as imagens para além do campo da arte, como um sistema de símbolos que "inclui a produção de ideias, narrativas, artefatos, objetos e mercadorias que se materializam na forma de livros, CDs, filmes, novelas, quadrinhos, tirinhas, publicidade, internet, etc" que "constituem e instituem mundos sociais na contemporaneidade"(MARTINS; TOURINHO, 2016, p.11-13).

A concepção intercultural se encontra presente nos estudos de Macedo (2013), Heimbach (2008) e Richter $(2002,2003,2008)$ que questionam o currículo colonizado e colonizador de artes visuais, pautado pela história da arte de raiz europeia que difunde o universalismo da arte ocidental orientada para a formação de identidades "forjadas em branco" (MACEDO, 2013). Em contraposição a essa hegemonia, promovem a emergência da interculturalização do currículo pela perspectiva do ensino de artes visuais voltado para a participação ativa em uma rede de relações e trocas não hierarquizadas de saberes, pensamentos, estéticas e memórias que fortaleçam a autoestima, auto-confiança e empoderamento de sujeitos pertencentes a grupos culturais invisibilizados e/ou subalternizados na escola e na sociedade. 
Segundo Richter (2003), a adoção de uma conceituação aberta e não excludente de arte é condição necessária para a interação dos conhecimentos artísticos consagrados pela cultura escolar com aqueles oriundos da estética do cotidiano dos/as alunos/as e do entorno da escola.

Trabalhar com a multiculturalidade no ensino de Arte supõe ampliar o conceito de arte, de um sentido mais restrito e excludente, para um sentido mais amplo, de experiência estética. Somente desta forma é possível combater os conceitos de arte oriundos da visão das artes visuais como "belas-artes", "arte erudita" ou "arte maior", em contraposição à ideia de "artes menores" ou "artes populares". A própria denominação de folclore e artesanato já vem carregada de preconceito, pois o termo "folklore" foi utilizado para representar a arte "do outro", daquele que não tinha acesso às camadas mais eruditas da sociedade, e o termo artesanato tem sido vinculado à ideia da reprodução sem criação, ou sem maior perfeição técnica. (RICHTER, 2003, p. 91)

Para Richter o ensino de artes visuais precisa ser um meio que possibilite a visibilização das diferenças culturais "como recursos que permitam ao indivíduo desenvolver seu próprio potencial humano e criativo, diminuindo o distanciamento entre arte e vida". (2003, p. 51).

A Educação Crítica para a Cultura Visual tem sido uma vertente pulsante no cenário educacional brasileiro, conforme atesta a Coleção Cultura Visual e Educação, organizada por Raimundo Martins e Irene Tourinho, professores da Universidade Federal de Goiás, e publicada pela Editora da Universidade Federal de Santa Maria, no Rio Grande do Sul, que até 2016 contava com sete volumes dedicados a veicular a produção de conhecimento articulado com a docência para deflagrar novos rumos educativos a partir do campo da cultura visual.

Para Fernando Hernandez, a principal referência internacional dessa tendência no Brasil, a cultura visual é "uma forma de discurso, um espaço pós-disciplinar de investigação e não uma determinada coleção de textos visuais" (2007, p. 18). Esse autor propõe que se busque compreendê-la criticamente na educação escolar estabelecendo interlocuções com outras áreas de conhecimento e temas do mundo atual, a fim de contribuir para

o aparecimento de "atores" com capacidade de ação e resistência. Não para falar do que "se vê" na verdade da representação, mas para reconhecer como cada um "se vê" e é colocado em práticas de discurso. Enfim, como estratégia para provocar posições alternativas e projetar-se em outros relatos. (HERNÁNDEZ, Ibidem, p. 17)

A sua concepção define-se a partir da crítica à narrativa hegemônica definida por ele da seguinte maneira:

A narrativa predominante em nossas escolas é a que se conecta com a tradição civilizatória gerada com a expansão colonizadora europeia desde o século XVI e, de maneira especial, desde o século XVII com os impérios britânico e francês. Um dos resultados desta narrativa é a construção de uma visão do "nós" e dos "outros" de- 
terminada pela hegemonia do homem branco, cristão e ocidental (europeu então e agora, sobretudo, norte-americano). Esta narrativa projeta-se na seleção de alguns conhecimentos escolares na qual o "outro" (aquele que não faz parte do "nós" hegemônico) é apresentado em posição de subordinação - pela qual há de ser civilizado e, portanto, é apresentado em posição, justificadamente explorado e despojado de seus saberes. A partir disso é que, em grande parte, a visão que se apresenta na Escola sobre o conhecimento e os saberes é mediada pela ideia da dominação cultural que faz com que se veja/ trate o outro como subalterno. Este outro seria o menino, a menina (crianças) e os jovens e, em parte, os docentes e as famílias" (HERNANDEZ Ibidem, p. 13)

De acordo com esse entendimento, as imagens são tomadas como agentes sociais da educação, pela influência e impacto sobre a vida das pessoas de forma a produzir "significados e valores que nos constituem como sujeitos, indivíduos, identidades e subjetividades” (MARTINS; TOURINHO, 2016, p. 12). Portanto, o que se propõe é tornar relevante a relação entre o que acontece no mundo visual contemporâneo e aquilo que é ensinado na escola.

\section{Ensino de artes visuais no "Pedrão": currículo assimilacionista e epistemologia eurocentrada}

Como nós somos eurocêntricos, né? A gente conhece muito da Europa e a gente não sabe nada da América Latina. A gente não é unido pelo que é nosso. A gente precisa colocar a escola num divã. $\mathrm{O}$ ensino de artes num divã. (Nando, professor de Artes Visuais do CP II)

Existem basicamente duas construções curriculares de Artes Visuais no CP II: o currículo do "Pedrinho" - denominação dada aos campi exclusivos de Educação Fundamental / Anos Iniciais (EF1) -, que compreende os programas do $1^{\circ}$ ao $5^{\circ}$ ano, e encontra-se estruturado por eixos temáticos que dão ênfase a relação entre arte e cultura/s; e o currículo do "Pedrão" - denominação dada aos campi destinados à Educação Fundamental / Anos Finais (EF2) e/ou Ensino Médio (EM)-, estruturado pela lógica linear da história da arte com uma narrativa que se inicia na Arte da Pré-história, no $6^{\circ}$ ano do EF2, e vai até a Arte Contemporânea, no $1^{\circ}$ ano do EM.

A seguir apresentamos e analisamos o currículo de Artes Visuais de acordo com a ordem cronológica em que surgiram e que foi determinante para a conformação de suas concepções educativas. Por isso começamos pelo currículo do "Pedrão", ao qual lançamos o olhar da Sociologia das Ausências, e em seguida passamos ao currículo do "Pedrinho", que será trabalhado na ótica da Sociologia das Emergências.

A Educação Artística foi implantada no Colégio durante os anos 1970, no antigo ensino secundário, sob a desconfiança de ser uma "matéria sem matéria", um espaço-tempo recreativo e de atividades decorativas/ornamentais, existente na escola para que os/as estudantes descansassem do cerebralismo exigido nas disciplinas de excelência, especialmente aquelas de cunho científico (ZORDAN, 2010). 
Nas décadas de 1980 e 1990, frente ao desafio de alcançar legitimidade e estabelecer a nova disciplina no disputado espaço da grade curricular acadêmica, os/ as professores/as buscaram dotar a disciplina de um sistema coeso, estável e distinto, composto por um corpo de conhecimentos específicos com o qual ela constituiu a sua identidade, estrutura e funcionamento, estabelecendo a história da arte eurocêntrica como eixo curricular.

Em 2017, o currículo do "Pedrão" encontrava-se estruturado em trimestres pela seguinte ordenação de conteúdos e pontos nodais $(\mathrm{PN})^{2}$. No $6^{\mathrm{a}}$ ano $-1^{\circ}$ trimestre (1T): Arte Popular e Estudo das Cores (PN - Estudo das Cores Primárias, Secundárias, neutras, quentes, frias); 2T) Arte Pré-Histórica: Brasil, América Latina e Europa (PN - Arte Rupestre: Escultura, Pintura e Gravura.); Arte Indígena (PN - Arte dos Povos Indígenas) e Arte Africana (PN - Arte Africana: a Lei da Frontalidade e a representação estilizada); 3T) A Arte das Grandes Civilizações (PN - Arte Grega / Idealismo e Arte Romana / Realismo). No 7o ano - 1T) Estudo das Cores (PN - Cores análogas e complementares); Estudo do Espaço/Forma (PN - espaços bi e tridimensional); 2T) Arte Medieval: Paleocristã, Bizantina, Gótica e Românica (PN - Arte e religião: arte medieval); 3T) Renascimento e Barroco na Europa (PN - Classicismo na arte / Grécia, Roma e Renascimento). No $8^{\circ}$ ano - 1T) Patrimônio Histórico e Artístico (PN - Características do urbanismo e arquitetura coloniais; características gerais do Barroco europeu e brasileiro); 2T) Arte Colonial Brasileira (PN - Espaço forma e cor / simetria, assimetria, formas estáticas e dinâmicas, ritmo e movimento); 3T) Arte Acadêmica no Brasil (PN - Academicismo no Brasil). No $9^{\circ}$ ano - 1T) Arte como Mimeses e Arte como expressão (PN - O impressionismo e os artistas precursores da arte moderna que romperam com os ideais estéticos acadêmicos); 2T) Arte Moderna (PN - cubismo, expressionismo, dadaísmo, surrealismo e abstracionismo); 3T) Modernismo no Brasil (PN - Modernismo no Brasil e na América Latina: influências europeias e identidades nacionais). No $1^{\circ}$ ano do EM: A conceituação da Arte; Arte, comunicação e linguagens visuais ( $\mathrm{PN}$ - Diferenciação entre a estética clássica, moderna e contemporânea); As linguagens artísticas tradicionais, modernas e contemporâneas (PN: Dadaísmo, a origem da arte contemporânea); Diferenciação entre as estéticas clássica, moderna e contemporânea (PN - Principais conceitos e linguagens); Dadaísmo, Pop Art e Arte Conceitual (PN - Pop Art e Arte Conceitual, os primeiros movimentos da arte contemporânea).

Dos vinte e quatro pontos nodais dos programas do $6^{\circ}$ ano do EF2 ao $1^{\circ}$ ano do Ensino Médio, dezoito são conteúdos relativos à história da arte (75\%). São eles: Arte Rupestre, Arte Indígena, Arte Africana, Arte das Grandes Civilizações (Arte da Grécia e Roma Antiga), Arte Medieval (Paleocristã, Bizantina, Gótica e Românica), Arte Clássica (Arte Greco-romana e Renascentista), Arte Colonial (Barroco europeu e brasileiro), Academicismo no Brasil, Impressionismo e Pós-Impressionismo, Arte Moderna (Cubismo, Expressionismo, Surrealismo, Abstracionismo), Modernismo no Brasil, Modernismo na América Latina, Dadaísmo, Pop Art e Arte Conceitual. Dez deles são conteúdos específicos da história da arte europeia (42\% do total de pontos nodais e $55 \%$ dos pontos nodais referentes à história da arte) e três são conteúdos específicos da arte brasileira erudita (o que corresponde a $12 \%$ do total de pontos nodais e $16 \%$ dos pontos nodais referentes à história da arte). Fora do eixo 
Europa-Brasil, apenas três conteúdos estão prescritos: Arte Indígena, Arte Africana e Modernismo na América Latina (o que corresponde a $12 \%$ do total de pontos nodais e $16 \%$ dos pontos nodais referentes à história da arte). A Arte Popular consta entre os conteúdos, mas não chega a alcançar o status de ponto nodal ${ }^{3}$.

De acordo com a Sociologia das Ausências, é possível verificar uma linha abissal que conduz essa narrativa histórico-linear eurocêntrica que começa a ser traçada no $6^{\circ}$ ano do EF2 ao estabelecer a localização temporal da Arte Africana e da Arte Indígena antes da Arte das Grandes Civilizações (na verdade, apenas Grécia e Roma), logo após a Arte Pré-histórica. Posteriormente, elas são invisibilizadas pelo fluxo da sequência seguinte: no $7^{\circ}$ ano do EF2, a arte italocêntrica; no $8^{\circ}$ ano do EF2, a arte barroca (o primeiro fluxo artístico da colonização cultural europeia) e a arte imperial (o segundo fluxo artístico da colonização cultural europeia); no $9^{\circ}$ ano do EF2, a arte moderna (terceiro fluxo artístico da colonização cultural europeia); no $1^{\circ}$ ano do EM, os movimentos da primeira etapa da arte contemporânea, ainda bastante referenciados na arte da Europa e dos Estados Unidos.

A Arte Africana e a Arte Indígena, assim como a Arte Popular, são situadas no início da narrativa histórico-linear, por meio de um artifício de assimilação (a inclusão excludente) para a produção da inexistência das artes desses povos não ocidentais (SANTOS, 2010), que são encapsuladas subliminarmente como manifestações de arte primitiva (conceito etnocêntrico a partir do qual derivam os termos arte naif e arte ingênua) a fim de justificar a universalidade das obras canonizadas da história da arte ocidental (PALERMO, 2014). Dessa forma se nega contemporaneidade à arte desses povos e se reproduz o "estigma tribal" (GOFFMANN, 2008) que desumaniza e desqualifica os sujeitos indígenas e afrodescendentes por meio dos binarismos civilizado-primitivo, progresso-atraso, cultura-natureza, "alta cultura"-"baixa cultura", erudito-popular. Em outras palavras, trata-se de uma estratégia de dominação epistemológica do pensamento abissal.

Esse currículo comporta conteúdos referentes à diversidade cultural, mas essa adição não altera a sua estrutura baseada na hegemonia de uma lógica monocultural assentada na universalidade dos saberes e valores (CANDAU, 2002). Ou seja, trata-se de uma "blindagem conceitual" da arte ocidental (VICTORIO FILHO, 2008), que define de forma colonizadora um ensino pautado pelo legado artístico europeu e sua transferência para o Brasil, e dessa maneira situa a arte brasileira na periferia do currículo de uma das principais escolas públicas brasileiras.

Importa destacar que essa estruturação curricular se encontra em sintonia com o Projeto Político Pedagógico do CP II elaborado no início do Século XXI ${ }^{4}$. Nesse documento encontra-se a afirmação de que "a escola é, por excelência, o espaço reservado à transmissão da cultura erudita” e a aprendizagem, sempre permeada pela cultura, realiza-se pelo processo de aquisição dessa cultura que "deve se dar no espaço escolar como um processo de substituição gradativa, através da intertextualidade, e não por imposição repentina” (BRASIL. 2002, ps. 67 e 68). 


\title{
Ensino de artes visuais no "Pedrinho": interculturalidade e descolonização
}

\author{
Você falar de multi e não entrelaçar é complicado, né? A gente aqui \\ é intercultural, porque a gente não apenas identifica. A gente iden- \\ tifica, mas entrelaça porque a nossa identidade é o entrelaçamento \\ de muitas culturas. [...] Então, se não entrelaçar essas diferenças \\ culturais a gente vai continuar achando que uma é mais importante \\ que a outra. E isso a gente não quer. (Inês, professora de Artes \\ Visuais do CP II)
}

O ensino de artes visuais do "Pedrinho" surgiu no início dos anos 1980 junto com a criação das unidades escolares destinadas ao EF1, sob a inspiração do ideário educativo construtivista. O corpo docente responsável por sua implantação defendeu a ideia de arte como experiência e a promoção de processos de aprendizagem centrados no fazer artístico e lúdico, sem produzir dicotomia entre teoria e prática. Por isso, desde a sua origem esse trabalho coletivo não se ampara em textos e apostilas, não tem ponto nodal e nem provas.

Durante os anos 1990, e até o início do século XXI, os programas curriculares desse segmento foram orientados pelo paradigma da história da arte eurocêntrica. A virada conceitual se deu efetivamente a partir de 2008 quando se iniciou a reformulação que rompeu com o paradigma histórico-linear e se construiu o currículo por eixos temáticos. Em 2017 esse currículo encontrava-se estruturado em três trimestres da maneira como apresentamos abaixo.

No $1^{\mathrm{o}}$ ano - 1T) Arte e Corpo (Identidade e Imagem corporal); 2T) Arte e Infância (Infância e Cultura Popular); 3T) Arte e Paisagem (A paisagem ao meu redor; Artistas da Paisagem.). No $2^{\circ}$ ano - 1T) Arte e Natureza (Representações da natureza: tema, suporte e material); 2T) Arte Indígena (Identidade e valores culturais; código visual e a presença indígena no mundo contemporâneo.); 3T) Arte Popular (Artistas populares e suas poéticas). No $3^{\circ}$ ano - 1T) Arte e Identidade (Identidade, memória e herança cultural); 2T) Arte e Mitologia (multiculturalismo e interculturalidade); 3T) Arte Afro-brasileira (Cultura Brasileira; Matriz africana nas artes visuais; Músicas e visualidades africanas). No $4^{\circ}$ ano - 1T) Arte e Representação I (Pintura); 2T) Arte e Representação II (Escultura brasileira); 3T) Arte e Representação III (Arquitetura: edifícios e jardins da cidade do Rio de Janeiro). No 5o ano - 1T) Linguagem Fotográfica (história da arte moderna; imagem pictórica e fotográfica no Brasil e nas Américas; fotografia contemporânea); 2T) Mídias Contemporâneas (Imagem/enquadramentos e novas linguagens); 3T) O Trabalho do Artista na Contemporaneidade (Poéticas contemporâneas, experiências estéticas e espaços da arte).

A lógica estruturadora desse currículo e os conhecimentos privilegiados, assim como a concepção de conhecimento escolar a ela subjacente - conforme veremos a seguir -, fundamentam o entendimento de que essa proposta contém fortes sinais da emergência da educação intercultural no ensino de artes visuais nesse segmento de ensino básico do CP II. 
Do $1^{\mathrm{o}}$ ao $3^{\mathrm{o}}$ ano, os temas de identidade, herança cultural, memória e ancestralidade - temática referenciada ao multiculturalismo e à interculturalidade,conforme explicitado no referencial analítico proposto para $2^{\circ}$ trimestre do $3^{\circ}$ ano do EF1 - relacionam arte, cultura e vida social com indicações para o diálogo entre os conhecimentos artísticos e as experiências de vida dos/as alunos/as. Privilegia-se o entendimento de que os povos tradicionais não denominavam como arte os seus "fazeres especiais" que eram relacionados com a religião e o mito, e que posteriormente foram caracterizados como arte na lógica da cultura europeia.

Simultaneamente à desestruturação da lógica histórico-linear eurocêntrica (por exemplo: os conteúdos de Arte Medieval e Renascimento que compunham os antigos programas do $4^{\circ}$ e $5^{\circ}$ anos foram transformados nos temas referentes à Arte e Representação em que se procura focar as linguagens artísticas, as mídias contemporâneas e o trabalho do artista na contemporaneidade, de forma a indicar abordagens voltadas para as poéticas contemporâneas, as experiências estéticas e os espaços da arte nas sociedades atuais) buscou-se novos marcos, lógicas e objetos de pensar, vivenciar e produzir arte na escola.

Nesse sentido, foram verificadas as influências entre os professores/as das teorizações da educação para a cultura visual e do ensino intercultural de artes visuais. Em relação ao primeiro universo de referências, existe a acolhida do entendimento de que o amplo espectro de realidades multimidiáticas - entre elas os sistemas populares de comunicação - possui maior penetração na vida cotidiana dos/as estudantes do que a produção artística convencional. Existe o olhar crítico para o fato de que as novas gerações "vivem em redes" (via facebook, videogame e whatsapp, entre outras redes sociais), imersas em relações sociais cada vez mais mediadas por bens simbólicos permeados por representações estereotipadas e valores mercadológicos, que promovem o empobrecimento da experiência humana e participam ativamente da conformação do imaginário com "verdades" impostas, que disseminam a estigmatização das diferenças e o conformismo com a exclusão e a subalternidade dos/as diferentes.

Os/As professores/as se sentem desafiados a enfrentarem as questões de poder e representação contidas nas ausências e nas ênfases da volúpia audiovisual alucinante que envolve os/as estudantes. Porém, a valorização que fazem da educação crítica para a cultura visual.parte do entendimento do ensino de artes visuais em campo expandido, privilegiando os artefatos artísticos e incorporando novas visualidades ao universo da arte, e não o contrário. Nesse sentido, apesar do conteúdo ampliado em relação ao âmbito da arte-educação tradicional - o que é fundamental para a construção de uma perspectiva não eurocêntrica -, o entendimento disciplinar que privilegia os artefatos artísticos, predominante entre os/as professores/as atuantes no EF1, impede a sintonia integral com a pedagogia da cultura visual, conforme a concepção dos autores dinamarqueses Illeris e Arvedsen, por destoar do conceito de fenômeno visual que lhe é central.

Os fenômenos visuais abarcam tudo aquilo com que decidimos nos relacionar de forma consciente por meio da visão, como imagens, objetos, paisagens, espaços públicos e privados etc. Embora alguns artefatos, sobretudo obras de arte, detenham uma posição privile- 
giada no que tange à atenção visual nas culturas ocidentais, esses são concebidos apenas como uma pequena parte dos fenômenos visuais relevantes para o currículo da pedagogia da cultura visual. (ILLERIS; ARVEDSEN, 2016, P. 25)

A professora Inês explicitou a concepção de conhecimento escolar que orienta o trabalho por eixos temáticos de acordo com ideia da arte em campo expandido. Segundo ela, há de se considerar os conteúdos como temas que possuem "películas" que separam sutilmente os conhecimentos escolares específicos de Artes Visuais das questões para além da arte que também se pretende trabalhar em diálogo com as experiências de vida dos sujeitos, especialmente aquelas oriundas da estética do cotidiano dos/as alunos/as e do entorno da escola.

Nesse sentido, a alfabetização visual e a construção do conhecimento ocorrem em sintonia com a leitura e a interpretação do mundo visual contemporâneo, a partir de visualidades relacionadas principalmente ao universo da arte contemporânea, da arte popular e das demandas por reconhecimento dos legados artísticos indígenas, africanos e afro-brasileiros.

As rotas pedagógicas enunciadas se apresentam em sintonia com o entendimento de Mason (2000), educadora inglesa com influência no Brasil no início do século XXI, para a qual o multiculturalismo impacta o campo da arte porque visa romper com as invenções modernas, a visão estética baseada na distinção entre arte superior e arte popular, a celebração das culturas ocidentais, e opõe-se ao eurocentrismo, o essencialismo e o transcendentalismo.

Nessa direção percebe-se ainda a adoção de preceitos da educação antirracista, que busca ir além da intervenção em casos de racismo e injúrias raciais na escola (e fora dela), para aprofundar o compromisso com a valorização da diferença em sala de aula e enfrentar as tensões e obstáculos presentes em processos de reconhecimento de sujeitos em situações de ensino-aprendizagem. Para tanto é fundamental a sua incidência sobre o currículo a fim de desconstruir o racismo epistêmico (CANDAU e OLIVEIRA, 2010) que promove a colonização cultural pela imposição dos conhecimentos produzidos pelo ocidente como os únicos legítimos e com capacidade de acesso à universalidade e à verdade.

A educação antirracista visa abrir fissuras no imaginário racial hegemônico para desconstruir a internalização da inferioridade racial e cultural que foi estabelecida historicamente pelo pressuposto colonialista de superioridade racial que constitui o padrão de branquitude e impõe políticas de poder e representação racistas na cultura escolar brasileira (CARDOSO JUNIOR, 2016).

No "Pedrinho", em acordo com essa visão, se buscar projetar curricularmente temas que levem ao empoderamento de crianças invisibilizadas e com baixa autoestima, por meio de ações pedagógicas que se habilitam ao enfrentamento do tabu histórico de não tratar de racismo na escola. O tema Arte e Afro-brasilidade, por exemplo, é abordado a partir da ancestralidade africana relacionando-a com a memória do povo brasileiro, as questões étnico-raciais e suas dimensões estéticas, políticas, 
religiosas e familiares. São apresentados vários povos africanos (assim como se faz em relação às diversas etnias indígenas) e busca-se desconstruir a ideia do negro escravizado, triste, submisso. Segundo a professora Imara, de Artes Visuais:

Quando a gente trabalha em artes os símbolos, e discute os sentidos daquelas simbologias, você mostra um rei e escuta: "Pô, mas um negro era rei?” Ele era rei e veio para o Brasil com uma história. Ele tinha a sua história com momentos de dança, de alegrias. Não era só aquela coisa da tristeza que muitos livros de História colocam. [...] Eu acho que o trabalho consiste em você elevar a autoestima e tirar essa máscara em torno do sofrimento da escravidão. A gente procura mostrar as coisas positivas, a grandiosidade que tem a cultura afro-brasileira.

De acordo com a entrevistada, essa abordagem requer uma opção política do/a professor/a em trabalhar para valorizar a cultura afro-brasileira ou contribuir para que o/a aluno/a negro/a continue "todo encolhidinho em sala de aula". Em outras palavras, significa optar entre defender a hegemonia da educação colonizada e colonizadora no Brasil ou apostar na interculturalização e na descolonização da educação com investimentos nas Epistemologias do Sul e na promoção em ecologias de saberes na escola.

\section{Desafios para a docência intercultural em Artes Visuais}

Pensar num projeto de formação intercultural de professores significa pensar num novo profissionalismo docente entre nós. (Professor Paulo Pires de Queiróz) $)^{5}$

Intolerância, racismo, machismo, xenofobia, exclusão e desigualdades de toda ordem (econômicas, políticas, sociais, raciais, sexuais, gênero, culturais, religiosas etc.) são, infelizmente, fenômenos que se multiplicam em tempos de globalização e que não afetam do mesmo modo os diferentes grupos sociais existentes nas sociedades contemporâneas. Eles são ingredientes dos confrontos explosivos que transtornam a vida em sociedade e tornam cada vez maior a necessidade de aprendermos a conviver articulando igualdade e diferença (CANDAU, 1994).

Os debates, análises e produções teóricas em torno do multiculturalismo compreendem concepções que variam quanto a sua capacidade de promover ou de obstaculizar os processos de construção da cidadania dos grupos que são diversos, cultural e racialmente, do padrão monocultural. No campo da educação, ele inclui tanto o olhar da diversidade cultural pelo exotismo e pelo folclore, passando por visões de assimilação cultural, até perspectivas mais críticas de desafio a estereótipos e a processos de construção das diferenças.

Macedo (2013) destacou que apesar da unanimidade (quase uma obviedade) em torno da presença de múltiplas culturas nos currículos de Artes Visuais, a maioria dos conteúdos presentes nas escolas apresenta homogeneidade e privilegia saberes relacionados à arte ocidental em detrimento da arte de outros povos, mantendo-se as relações de dominação e submissão cultural histórica. 
Camille Paglia (2014), que defende uma educação artística baseada num quadro histórico de conhecimentos objetivos acerca dos estilos e símbolos da "Grande Arte”, junto com a valorização da linha histórica de influência artística na cultura ocidental (desde o Egito antigo até a atualidade), sem entendê-la como uma "narrativa" arbitrária e imperialista, critica o movimento multiculturalista nos Estados Unidos, que se seguiu à década de 1960, pois compreende que diante da oportunidade para expandir o conhecimento do mundo da arte ele optou por abordagens que com demasiada frequência têm sacrificado a erudição e a sua cronologia tradicional.

Sobre tais colocações que reclamam atenção para questões complexas ao processo de construção de um ensino interculturalmente crítico de artes visuais na educação escolar, importa perguntar o seguinte: que sacrifícios à erudição e à cronologia ocidentalocêntrica, estabelecida pela colonização da arte, um ensino descolonizado e referenciado no marco da interculturalidade precisa realizar para subverter a lógica hegemônica?

No estudo de caso apresentado objetivou-se saber sobre a concepção de interculturalidade existente no ensino de artes visuais na educação institucionalizada, principalmente em relação as suas implicações para o currículo e o potencial que possui para desestabilizar concepções consolidadas de conhecimentos/saberes e conteúdos escolares dessa disciplina escolar.

Verificou-se a construção de um caminho para a interculturalização por via da ação simultânea de rompimento com o paradigma curricular eurocêntrico e a produção coletiva de uma nova concepção de conhecimentos formalizados de artes visuais centrado na ideia de arte em campo expandido. Tal alternativa, em diálogo com as teorizações da educação para cultura visual, vem ensejando novas rotas pedagógicas voltadas para a promoção da inter-cultura como interepistemologia, em contraposição a uni-versalidade ocidental. De acordo com a proposição de ecologia de saberes, a proposição curricular do Pedrinho busca propiciar a participação ativa dos sujeitos escolares em uma rede de relações e trocas não hierarquizadas de saberes, pensamentos, estéticas, memórias e sensações.

Essa transformação curricular ocorrida a partir da adoção do currículo por eixos temáticos, colocou em questão um modelo objetivado e fixo de saberes formalizados, codificados e sistematizados em que predominam a abordagem formalista e a concepção da "arte pela arte"6. Ela propiciou uma alternativa crível ao currículo ordenado pela lógica da unilinearidade histórica assentada em conteúdos programáticos inflexíveis, supostamente "neutros" e "inevitavelmente" pré-requisitários.

Essa mudança provocou efeito sobre o ensino de artes visuais do Colégio Pedro II como um todo ao contribuir para a consciência do privilégio do enfoque colonialista que não dá a ver que a opção eurocêntrica não utiliza as terminologias Arte Europeia e Arte Estadunidense, ao mesmo tempo em que categoriza as "outras" artes visuais, de outros povos, pelas terminologias Arte Indígena, Arte Africana, Arte Afro-brasileira, Arte Popular. Ou seja, ele não abre mão da solércia que impede evidenciar a cartografia cognitiva que orienta os processos de ensino-aprendizagem em consonância com determinado discurso colonizado de identidade cultural brasileira. 
Esse estudo sinalizou sobre a importância da ação de professores/as para a desconstrução da monoculturalidade e a promoção da interculturalidade no ensino de artes visuais na escola básica. O que tem colocado para essa coletividade a necessidade de reinvenção da base identitária docente etnocêntrica forjada principalmente na formação inicial de professores/as de artes visuais, devido a forte tendência eurocêntrica existente nos cursos superiores no Brasil.

Nesse sentido, duas observações emergiram desse estudo, ambas assinaladas pelos docentes do Colégio Pedro II. A primeira delas ressalta a visão de que a interculturalidade precisa ser tomada como um princípio educativo na formação inicial e continuada. E para tanto não se pode prescindir da sintonia entre a conduta profissional e a filosofia de trabalho com o compromisso pessoal de docentes (valores de vida e exercício da cidadania).

A segunda indica que a construção de um novo profissionalismo docente em artes visuais, compromissado com a interculturalidade, o antirracismo e a descolonialidade do pensamento pedagógico, não pode prescindir de investimentos na formação do/a professor/a-pesquisador/a conjugado com a dimensão de professor/a curador/a, no sentido mesmo do/a professor/a como organizador da cultura (Giroux, 1997) e não como um/a técnico/a programado/a para aplicar de maneira inflexível os conhecimentos curriculares invariáveis.

\section{Referências}

BRASIL. Ministério da Educação. Secretaria de Educação Fundamental. Colégio Pedro II: Projeto Politico Pedagógico/ Colégio Pedro II. Brasília, DF: Inep/MEC, 2002.

CANDAU, Vera. Multiculturalismo e Educação: a construção de uma perspectiva. Cidadania e Pluralidade Cultural: questões emergentes. In: CANDAU, V. (Org.) Sociedade, Educação e Cultura(s): questões e Propostas. 1. ed. Petrópolis, RJ: Vozes, 2002.

CANDAU, Vera. Educação Escolar e Cultura(s): multiculturalismo, universalismo e currículo. In: CANDAU, Vera. (org.) Didática: questões contemporâneas. Rio de Janeiro, RJ: Forma \& Ação, 2009.

CANDAU, Vera. Apresentação. In: CANDAU, Vera. (org.). Interculturalizar, descolonizar, democratizar: uma educação "outra”? Rio de Janeiro, RJ: 7Letras, 2016.

CARDOSO JUNIOR, Wilson. Ensino de artes visuais antirracista: reflexões sobre uma prática pedagógica. In: CANDAU, Vera. Interculturalizar, descolonizar, democratizar: uma educação "outra'? Rio de Janeiro, RJ: 7 Letras, 2016.

DANTO, Arthur C. O abuso da beleza: a estética e o conceito de arte. São Paulo: Editora WMF Martins Fontes, 2015.

GIROUX, Henri. Professores como intelectuais: rumo a uma pedagogia crítica da aprendizagem. Porto Alegre: Artes Médicas, 1997.

GOFFMAN, Erving. Estigma. Buenos Aires, Argentina: Amorrurtu, 2008.

ILLERIS, Helene; ARVEDSEN, Karsten. Fenômenos e eventos visuais: reflexões sobre currículo e pedagogia da cultura visual. In: MARTINS, Raimundo; IRENE, Tourinho (orgs.) Culturas das imagens: desafios para a arte e para a educação. Santa Maria, RS: Editora da UFSM, 2016. 
HEIMBACH, Nilva. Cultura regional e o ensino da arte: caminho para uma prática intercultural? Estudo de caso: Escola Municipal Sulivan Silvestre de Oliveira - Tumune Kalivono “Criança do Futuro". 2008. 138 p. Mestrado em Educação na Universidade Católica Dom Bosco, Campo Grande, 2008.

HERNÁNDEZ, Fernando. Catadores da cultura visual: transformando fragmentos em nova narrativa educacional. Porto Alegre, RS: Mediação, 2007.

MACEDO, Juliana Gouthier. Identidades forjadas em brancos: ensino de arte e interculturalidade. 199 p. Tese (Doutorado em Artes) - Programa de Pós-Graduação em Artes, Escola de Belas Artes, Universidade Federal de Minas Gerais, Belo Horizonte / MG, 2013.

MARTINS, Raimundo; IRENE, Tourinho. Prefácio da Primeira Edição. In: MARTINS, Raimundo; IRENE, Tourinho (orgs.) Culturas das imagens: desafios para a arte e para a educação. Santa Maria, RS: Editora da UFSM, 2016.

MASON, Rachel. Por uma arte-educação multicultural. Campinas, SP: Mercado das Letras, 2001.

OLIVEIRA, Luiz Fernandes; CANDAU, Vera. Pedagogia decolonial e educação antirracista e intercultural no Brasil. Educação em Revista, Belo Horizonte: UFMG, v. 26, n.1, p. 15-40, abr. 2010.

PAGLIA, Camille. Imagens Cintilantes: uma viagem através da arte desde o Egito até a "Star Wars”. Rio de Janeiro, RJ: Apicuri, 2014.

PALERMO, Zulma. El arte latino-americano em la encrucijada decolonial. In: PALERMO, Zulma. (org.). Arte y estética em la encrucijada descolonial. Ciudade Autónoma de Buenos Aires, Argentina: Del Signo, 2014.

RICHTER, Ivone. Interculturalidade e estética do cotidiano no ensino das artes visuais. São Paulo, SP: Mercado de letras, 2003.

RICHTER, Ivone. Multiculturalidade e Interdisciplinaridade. In: BARBOSA, A.M. (org.) Inquietações e mudanças no ensino da arte. São Paulo, SP: Editora Cortez, 2002.

RICHTER, Ivone. Arte e interculturalidade: possibilidades na educação contemporânea. In: BARBOSA, A. M. (org.) Interterriorialidade - mídias, contextos e educação. São Paulo, SP: Editora Senac São Paulo; Edições SESC SP, 2008.

SACAVINO, Susana. Educação descolonizadora e interculturalidade: notas para educadoras e educadores. In: CANDAU, Vera. Interculturalizar, descolonizar, democratizar: uma educação “outra'? Rio de Janeiro, RJ: 7 Letras, 2016.

SANTOS, Boaventura Sousa. Renovar a teoria crítica e reinventar a emancipação social. São Paulo, SP: Boitempo, 2007.

SANTOS, Boaventura Sousa; MENESES, Maria Paula [Orgs.]. Epistemologias do Sul. São Paulo, SP: Cortez, 2010.

VICTORIO FILHO, Aldo. Ensino da arte hoje: desafios, sentidos e sintonias. In: REUNIÃO DA ASSOCIAÇÃO NACIONAL DE PÓS-GRADUAÇÃO E PESQUISA EM EDUCAÇÃO, 31. 2008, Caxambu. Anais. Caxambu: ANPEd, 19-22 out. 2008.

ZORDAN, Paola. Percurso das Artes Visuais: geologia de uma disciplina. REUNIÃO DA ASSOCIAÇÃO NACIONAL DE PÓS-GRADUAÇÃO E PESQUISA EM EDUCAÇÃO, 33. 2010, Caxambu. Anais. Caxambu: ANPEd, 17-20 out. 2010. 
${ }^{1}$ Esse trabalho resulta do estudo de doutorado intitulado Interculturalidade e ensino de artes visuais no Colégio Pedro II, defendido em 2017, junto ao Programa de Pós-Graduação em Educação da Pontifícia Universidade Católica do Rio de Janeiro. Para a sua realização foi feita uma pesquisa no Colégio Pedro II de 2013 a 2017. Os depoimentos e os demais dados contidos nesse trabalho resultam desse estudo.

${ }^{2}$ Pontos Nodais são os conteúdos definidos como os mais relevantes do programa de cada ano/série por serem aqueles que os/as alunos/as precisam dominar para se tornarem aptos/as a seguirem para o próximo ano/série no âmbito de cada disciplina escolar.

${ }^{3}$ A nova versão do currículo do Ensino Fundamental / Anos Finais mantém a estrutura orientada pela história da arte unilinear eurocêntrica com as seguintes modificações: $1^{\circ}$ ) a Arte Popular passou a integrar os Pontos Nodais do $1^{\circ}$ trimestre do $6^{\circ}$ ano; $2^{\circ}$ ) o conteúdo Arte das Grandes Civilizações foi retirado do programa do $6^{\circ}$ ano; $3^{\circ}$ ) o conteúdo Modernismo na América Latina foi retirado programa do $9^{\circ}$ ano. Essas modificações constam da apresentação do Departamento de Artes Visuais para o novo Projeto Político Pedagógico Institucional (PPPI) do Colégio Pedro II que ainda não foi publicado.

${ }^{4} \mathrm{O}$ novo Projeto Político Pedagógico Institucional (PPPI) do Colégio Pedro II já foi concluído e aprovado pelo Conselho de Ensino, Pesquisa e Extensão (Conepe) e pelo Conselho Superior (Consup) e está em fase de publicação que deverá ocorrer ainda no ano de 2018.

${ }^{5}$ Colocação feita pelo professor Paulo Pires de Queiróz na banca de dissertação de Fagner Henrique Guedes Neves, intitulada "Conhecimento, Escola e Cultura/s: ensino de sociologia e educação intercultural", realizada na Pontifícia Universidade Católica - Rio de Janeiro, no Programa de Pós-Graduação em Educação, em 24/03/2014.

${ }^{6}$ A “arte pela arte’ é uma expressão do formalismo, uma concepção que preconiza um modo universal de entender qualquer obra de arte considerando que nada fora dela é relevante para o entendimento crítico e estético que a distingue de outros objetos físicos, sendo a arte composta segundo princípios formais, independentemente de sua origem histórica ou cultural, a fim de demonstrar que "a beleza é a mesma em toda parte, independentemente da cultura e da história" (DANTO, 2015, p. 147).

* Professor-adjunto da Faculdade de Educação da Universidade Federal do Rio de Janeiro, Rio de Janeiro, Rio de Janeiro, Brasil.

** Professora emérita do Departamento de Educação da Pontifícia Universidade Católica do Rio de Janeiro, Rio de Janeiro, Rio de Janeiro, Brasil. 


\section{Correspondência}

Vera Maria Ferrão Candau - Pontifícia Universidade Católica do Rio de Janeiro, Centro de Teologia e Ciências Humanas, Departamento de Educação. Rua Marques de São Vicente, 225 - Gávea. CEP: 22453900. Rio de Janeiro, Rio de Janeiro, Brasil.

E-mail:wilcardosojr@gmail.com-vmfc@puc-rio.br

Recebido em 02 de junho de 2018

Aprovado em 30 de agosto de 2018

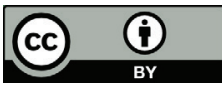

This work is licensed under a Creative Commons Attribution 4.0 International (CC BY 4.0). 
